\title{
BMJ Open Prevalence, determinants and knowledge about herbal medicine and non-hospital utilisation in southwest Nigeria: a cross-sectional study
}

\author{
Olujimi Aina, ${ }^{1}$ Lata Gautam (D) , ${ }^{1}$ Padam Simkhada, ${ }^{2}$ Sarah Hall ${ }^{3}$
}

To cite: Aina 0, Gautam L, Simkhada P, et al. Prevalence, determinants and knowledge about herbal medicine and non-hospital utilisation in southwest Nigeria: a crosssectional study. BMJ Open 2020;10:e040769. doi:10.1136/ bmjopen-2020-040769

- Prepublication history for this paper is available online. To view these files, please visit the journal online (http://dx.doi. org/10.1136/bmjopen-2020040769).

Received 27 May 2020 Revised 04 August 2020 Accepted 07 August 2020

Check for updates

(C) Author(s) (or their employer(s)) 2020. Re-use permitted under CC BY-NC. No commercial re-use. See rights and permissions. Published by BMJ.

${ }^{1}$ School of Life Sciences, Anglia Ruskin University-Cambridge Campus, Cambridge, UK ${ }^{2}$ School of Human and Health Sciences, University of Huddersfield, Huddersfield, UK ${ }^{3}$ Leicester School of Pharmacy, Health and Life Sciences, De Montfort University, Leicester, UK

Correspondence to

Dr Lata Gautam;

Lata.Gautam@anglia.ac.uk

\section{ABSTRACT}

Objectives To examine the prevalence, determinants, safety perceptions, effectiveness and knowledge of herbal medicines (HMs) and reasons for non-hospital utilisation.

Design Cross-sectional study.

Setting Ekiti state, southwest Nigeria.

Participants A representative sample $(n=1600)$ of adults (18 years or above) currently living in Ekiti state, southwest Nigeria for at least 2 years, at the time of study.

Results The majority of the respondents $(85 \% \mathrm{n}=1265)$ have used HMs in the last 2 years. Across economic classes use, middle income (88.3\%) was the highest $(p<0.001)$, suggesting poverty is not a major factor, even with income inequality. Their use was the most common among respondents with a primary level of education $(91.4 \%, p=0.001)$; and $100 \%$ use $(p=0.009)$ of respondents practising African traditional religion; farmers and those 70 years or above. Our study also reveals more men $(p<0.001)$ used HMs $(89.9 \%)$ than women $(78.6 \%)$ and effectiveness was a major reason for use (39.6\%) followed by affordability (31.9\%). Although the majority of the respondents $(90 \%)$ knew the difference between certified and uncertified HMs, uncertified ones were the most commonly used (37.3\%) in the population.

Conclusion Although there is a cultural history of HM use within the study population, the choice of use was based on their effectiveness. Therefore, a scientifically valid analysis of this claim within the study population may help achieve a cheaper and affordable healthcare alternative which will be safe. This is important, considering that uncertified HMs were chosen over certified ones, even though a large majority of respondents were aware of differences and likely consequences. This study highlights the need for further investment by the government, individuals and corporate stakeholders in HM research and improvement of conventional healthcare system. This is in addition to public health awareness on the danger of use of uncertified herbal products.

\section{BACKGROUND}

The provision of healthcare falls mainly into the orthodox and non-orthodox systems. The non-conventional healthcare system includes complementary medicine of which herbal medicine (HM) is an important component. ${ }^{1}$ HMs are defined as materials or preparations
Strengths and limitations of this study

Qualitative and quantitative data used in this research catered for the peculiarity of the study population, hence increasing inclusivity.

- Most towns were visited during the day when some farmers may have been absent leading to a low number of participants from this group.

- This study found that the timing of questionnaire administration is an important consideration to make.

- There were more incomplete entries in the selfadministered questionnaires compared with the interview-administered ones.

obtained from one or more plants-raw or processed parts ${ }^{2}$ - containing substances with therapeutic characteristics and other benefits to human health. A large percentage of the world's population depends on HMs in both developing $(80 \%)^{3} 4$ and developed countries. $^{56}$

The use of HM is pivotal to the practice of the African traditional medicine (ATM), and it was the major medical system available to millions of people in urban and rural communities of Africa, until the advent of Europeans. ${ }^{78}$ It is a non-conventional system of disease management that employs various processes of consultation with herbalists, priests, media and diverse traditional deities together with herbal use. ${ }^{9}$ The practice of ATM also extended to culturally homogeneous ethnic groups in Yoruba land called the "Ekitis" ${ }^{10}$ who form the present Ekiti state. Culturally, the larger Yoruba ethnic group had the Babalawo and Onisegun as traditional medical practitioners and specialists in herbs, respectively, as healthcare providers ${ }^{11}$ whose existence and practice are still contemporary.

Although, until recently HM in Africa was generally not thoroughly researched and only loosely regulated ${ }^{12}$ with the lack of proper documentation of the workings of the ATM 
and its practice not helping. ${ }^{13}$ Some of these factors caused the pericolonial conflict between new orthodox systems and the already established ATM, largely due to the belief by the colonialists that the latter was superstitious ${ }^{14}$ and therefore declared illegal. ${ }^{15}$ The perpetuation of this perception and the lack of proper documentation, research and regulation may still militate against an improved synergy between stakeholders, researchers and collaboration between HM and orthodox medicine. This also includes the general public who are caught between both choices for numerous reasons.

However, recent studies have reported the high use of HMs in Nigeria. ${ }^{16-20}$ A study conducted in one of the local governmentareas (Ekiti state) reported $74.3 \%$ of the respondents used HM in the treatment of malaria. ${ }^{16}$ In another study, in urban Lagos Nigeria, 66.8\% (n=388 respondents) used HM for management of various ailments. ${ }^{20}$ However, these studies are more specific to setting and disease, hence a need for a general population study and non-disease specific study as reported here. Moreover, the knowledge and prevalence of HM use within the larger population in Ekiti state remains unknown, researched or documented; although its use is generally believed to be widespread.

Vendors of various HMs are almost now ubiquitous in Nigeria, trading in traffic gridlocks, highways, bus stops/ stations, festivals and even in some conventional health facilities, but the determinants of its use has not been wholly examined. HMs used are either locally made, refined, imported, certified or uncertified by the government. The National Agency for Food and Drug Administration and Control (NAFDAC) in Nigeria is the government agency responsible for the certification, registration and regulation of HMs. Extemporaneous HMs (herbs or mixture of herbs given on a one-to-one basis) are not included in the class of HMs. ${ }^{21}$ However, some of these products have now been commercialised raising concerns about safety as much as the uncertified HM types, therefore these need to be included in the NAFDAC registration and regulation process.

Patronage of conventional health facilities is an important aspect of healthcare delivery system in most communities. The conventional and traditional medical system provides healthcare services in Ekiti state, coordinated by the State Ministry of Health. ${ }^{22}$ The increased use of HMs has been attributed to challenges relating to the availability and affordability of conventional medicine. This may be true considering that $40.1 \%$ of the total population of Nigeria are poor and live on less than 137430 naira (US\$352) annually. ${ }^{23}$

In Ekiti state, of the 16 local government areas, only 2 areas (Irepodun/Ifelodun and Ekiti East) have a higher number of their population using their health facilities optimally. ${ }^{24}$ However, with the highest poverty head count being $87.7 \%$ in Sokoto northwest Nigeria and $4.5 \%$ in Lagos southwest Nigeria, Ekiti state has a poverty head count of $28 \% .^{23}$

Therefore, use of HM is likely a combination of different factors within the study population, hence this study investigated the knowledge, prevalence and determinant of HM use and the reasons for non-utilisation of conventional health facilities in Ekiti state, Nigeria. The result from this study should help in policy formulation by the government and stakeholders towards improved healthcare access, areas of further research and collaboration. This will be in addition to identification of areas for public health intervention and targeting, which will improve the health outcome of the population.

\section{METHODS}

\section{Study design}

This was a cross-sectional study conducted in Ekiti state, southwest Nigeria with a population of $2384212,{ }^{25}$ which include over 127 large and small towns. ${ }^{26} \mathrm{~A}$ semistructured survey was conducted to examine HM use. Participants were 18 years and above and those who lived in Ekiti state at the time of study or have lived in the state for at least 2 years.

The Cochran formula was used for determination of the minimum sample size required in this study. It allows for calculation of the best possible size with preferred precision and confidence level. It is particularly suitable for large study populations and calculates the sample size based on a proportion of people who use HM. ${ }^{27}$

Hence, the minimum sample size required for this study was 1067 participants assuming $50 \%$ of the population use ${ }^{27} \mathrm{HM}$ as calculated using equation 1 :

$$
\mathrm{n}=\frac{\mathrm{Z}^{2} \times \mathrm{pq}}{\mathrm{d}^{2}}
$$

Where $\mathrm{n}=$ required minimum sample size in the study $\mathrm{z}=\mathrm{Z}$-score or SD

$p=$ proportion of people who use HM in the study area $\mathrm{q}=1-\mathrm{p}$

$\mathrm{d}=$ the acceptable error level

The calculation of the sample size was based on acceptable error level of $3 \%(0.03)$ and a CI of 95\% corresponding to a Z-score of 1.96 . These are within social science research recommended values for SD and error levels. $^{28}$ The proportion of people using HM in Ekiti state is unknown, therefore maximum heterogeneity was assumed (ie, a 50/50 split in users and non-users) with $\mathrm{p}=0.5$.

\section{Sampling method}

The study participants were selected using a multistage sampling technique. The first stage involved stratifying Ekiti state into the existing 16 local government areas. This followed random sampling to select two towns in each local government (total of 32 towns- second stage). Then residential quarters in each town were selected randomly, making a total of 160 residential quarters (third stage). Systemic random sampling was used in the fourth stage in selecting 10 households from each of the selected residential quarters and one participant from each household made up the final sample population of 1600 . Hence, a cross-sectional study was administered to 
1600 participants which was above the required minimum sample size as determined earlier and were representatives of the Ekiti state population. ${ }^{25}$ A flow diagram of the sampling method is shown in online supplemental file 1 .

\section{Administration and measurement of research instrument}

The questionnaire used in this study was adapted from previous studies on the use of $\mathrm{HMs}^{181929}$ and validated in a pilot study. They were interviewer-administered or selfadministered depending on the ability or choice of the participant. A total of 10 field enumerators with previous experience were employed from the public and trained to help with data collection. Each self-administered questionnaire was completed in about $10 \mathrm{~min}$ and the interview-administered in about $20 \mathrm{~min}$. The questionnaire was used to obtain both qualitative and quantitative data with open-ended and closed-ended questions, respectively. Interpretation of the questionnaire in the local dialect was offered when required.

The close-ended questions were used to collect the sociodemographic data of the participants which included their age range, gender, level of education, religion, occupation and annual income. Close-ended questions were also asked to examine knowledge (asked if participants knew what HM was or not, and certification status), their perception of its effectiveness and safety, then the frequency of use among participants to assess prevalence of HM use. The open-ended questions were employed to identify reasons for HM preference and non-orthodox preference. These also included adverse effects experienced and how they were managed.

\section{Data analysis}

Manual representational thematic analysis was used to analyse textual data obtained from open-ended questions and presented quantitatively. In some instances where participants gave multiple answers to an open-ended question, each was analysed as individual response. Hence, the total of some responses in a category exceeds the 1265 total number of respondents. Afterwards, inferential and descriptive statistical analysis was carried out using SPSS (V.20.0). Comparison of sociodemographic factors and the use or non-use of HM was carried out using inferential statistics. A Pearson $\chi^{2}$ test was used to examine the impact of independent variables (eg, age, gender, religion, level of education, occupation, annual income) on various responses (such as use of $\mathrm{HM}$ and perception of safety) in the study and $\mathrm{p} \leq 0.05$ at $95 \%$ CI was considered to be statistically significant. Multicollinearity between the independent variable and the use of HM was also tested. When the variance inflation factor (VIF) and tolerance are greater than 5-10 and lower than $0.1-0.2$, respectively, this indicates multicollinearity.

\section{Patient and public involvement}

The public have participated in this study by completing the survey. The pilot study was carried out to determine its feasibility on a larger scale. It was observed that some of the questions on HM use were ambiguous. As a result, the questions were rephrased to focus on the use of HMs within the last 2 years. Research questions were developed from prior knowledge and experience of the researchers. Participants were not asked to assess the burden of the intervention and time required to participate in the research. Multistage sampling method was used for participants' recruitment.

\section{RESULTS}

A total of 984 questionnaires were self-administered while 616 questionnaires were interview based. Among these, 1265 respondents formed the final sample size for the study due to exclusion of 335 respondents' entry. A total of 263 self-administered and 72 interview-based questionnaires were excluded due to being incomplete.

\section{Sociodemographic characteristics of respondents}

There were more male respondents (56.4\%) than female respondents $(43.6 \%)$ in the study. Majority of the respondents $(43.2 \%)$ were within the age group of 30-49 years, Christians $(69.5 \%)$ and self-employed $(39.6 \%)$. In addition, the majority of the respondents $(82 \%)$ were within the low-income group as shown in table 1.

\section{Knowledge and use of HMs}

Considering their knowledge and use of HMs, 90\% of the respondents knew the difference between certified and uncertified HM, while $85 \%$ had used them in the last 2 years, $53 \%$ using them more than 10 times (table 2). However, over half of the respondents (57\%) believed it is unsafe to take uncertified HM, although $37 \%$ continued to take them, while $32 \%$ took both certified and uncertified HM.

\section{Preference for HM use and hospital utilisation}

The effectiveness was the reason $(39.6 \%)$ respondents preferred HMs and for those who did not use HMs, risk to health was the major reason $(61 \%)$. A $45.2 \%$ of users blamed poor service delivery for non-hospital utilisation (table 3).

According to figure 1, across all income classes, effectiveness of HM was the most attributed reason for their use. Likewise, poor service delivery was the most stated reason for non-utilisation of conventional health facilities (figure 2).

\section{Perception of safety and effectiveness}

To explore perception of safety and effectiveness of HMs, our survey results showed that the majority of the respondents $(83.6 \%)$ perceived that HMs are effective, while more than half $(57.3 \%)$ believed they are unsafe (table 4).

Most of the respondents $(52.7 \%)$ who have used HM in the last 2 years did not experience any adverse effects while some experienced abdominal discomfort (14\%), nausea and vomiting $(18.7 \%)$, headache $(7.6 \%)$, stooling $(5.8 \%)$ and generalised body weakness $(1.3 \%)$. These adverse 
Table 1 Sociodemographic background of the respondents

Frequency $\%$

\begin{tabular}{|c|c|c|}
\hline \multicolumn{3}{|l|}{ Age (years) } \\
\hline $18-29$ & 322 & 25.5 \\
\hline $30-49$ & 547 & 43.2 \\
\hline $50-69$ & 358 & 28.3 \\
\hline 70 and above & 38 & 3.0 \\
\hline \multicolumn{3}{|l|}{ Gender } \\
\hline Male & 713 & 56.4 \\
\hline Female & 552 & 43.6 \\
\hline \multicolumn{3}{|l|}{ Level of Education } \\
\hline No formal education & 191 & 15.1 \\
\hline Primary & 245 & 19.4 \\
\hline Secondary & 340 & 26.9 \\
\hline Tertiary & 489 & 38.7 \\
\hline \multicolumn{3}{|l|}{ Religion } \\
\hline Christianity & 879 & 69.5 \\
\hline Islam & 346 & 27.4 \\
\hline African traditional & 40 & 3.2 \\
\hline \multicolumn{3}{|l|}{ Occupation } \\
\hline Student & 84 & 6.6 \\
\hline Civil servant & 491 & 38.8 \\
\hline Farmer & 76 & 6.0 \\
\hline Self-employed & 501 & 39.6 \\
\hline Others & 113 & 8.9 \\
\hline \multicolumn{3}{|l|}{ Annual income (in naira) } \\
\hline Low $(\leq 600000)$ & 1037 & 82.0 \\
\hline Middle (600 000-2.4 million) & 179 & 14.2 \\
\hline High ( $\geq 2.4$ million) & 49 & 3.9 \\
\hline
\end{tabular}

Table 2 Knowledge and use of herbal medicines (HMs)

\begin{tabular}{|c|c|c|}
\hline & Frequency & $\%$ \\
\hline \multicolumn{3}{|c|}{ Knowledge of certified and uncertified HM } \\
\hline Have knowledge & 1139 & 90.0 \\
\hline Do not have knowledge & 126 & 10.0 \\
\hline \multicolumn{3}{|c|}{ Use of $\mathrm{HM}$ in the last 2 years } \\
\hline Used & 1075 & 85.0 \\
\hline Non-use & 190 & 15.0 \\
\hline \multicolumn{3}{|l|}{ Class of HM used } \\
\hline Uncertified & 401 & 37.3 \\
\hline Both & 343 & 31.9 \\
\hline Certified & 331 & 30.8 \\
\hline \multicolumn{3}{|c|}{ Frequency of HM use in last 2 years } \\
\hline Once-twice & 142 & 13.2 \\
\hline $3-10$ times & 363 & 33.8 \\
\hline Over 10 times & 570 & 53.0 \\
\hline
\end{tabular}

Table 3 Reasons for herbal medicine (HM) use/non-use and non-hospital utilisation

\begin{tabular}{lcc}
\hline & Frequency & $\%$ \\
\hline Reasons for HM use & & \\
\hline Effectiveness & 538 & 39.6 \\
\hline Affordability & 434 & 31.9 \\
Availability & 292 & 21.5 \\
\hline Natural product & 96 & 7.1 \\
Reasons for non-HM use & \\
\hline Risk to health & 116 & 61.1 \\
\hline Personal preference & 49 & 25.8 \\
\hline $\begin{array}{l}\text { Poor knowledge of } \\
\text { HM composition }\end{array}$ & 25 & 13.2 \\
\hline Reasons for non-hospital utilisation & \\
\hline Poor service delivery & 534 & 45.2 \\
\hline High hospital cost & 396 & 33.5 \\
\hline Unorthodox belief & 141 & 11.9 \\
\hline Do visit the hospital & 110 & 9.3 \\
\hline
\end{tabular}

effects were managed differently; the majority (42.5\%) took adequate rest while the effects self-limit, visited the hospital (25\%), took orthodox medicine $(21.6 \%)$ or took another HM (10.9\%) (see table 4).

The data have been analysed using Pearson $\chi^{2}$ test to explore if there is a significant association among different factors studied such as age, sex, level of education, religion, annual income and occupation, and the use of HM. As shown in table 5 , results indicate a significant association between, age, sex, religion, annual income and occupation with HM using $95 \%$ CI.

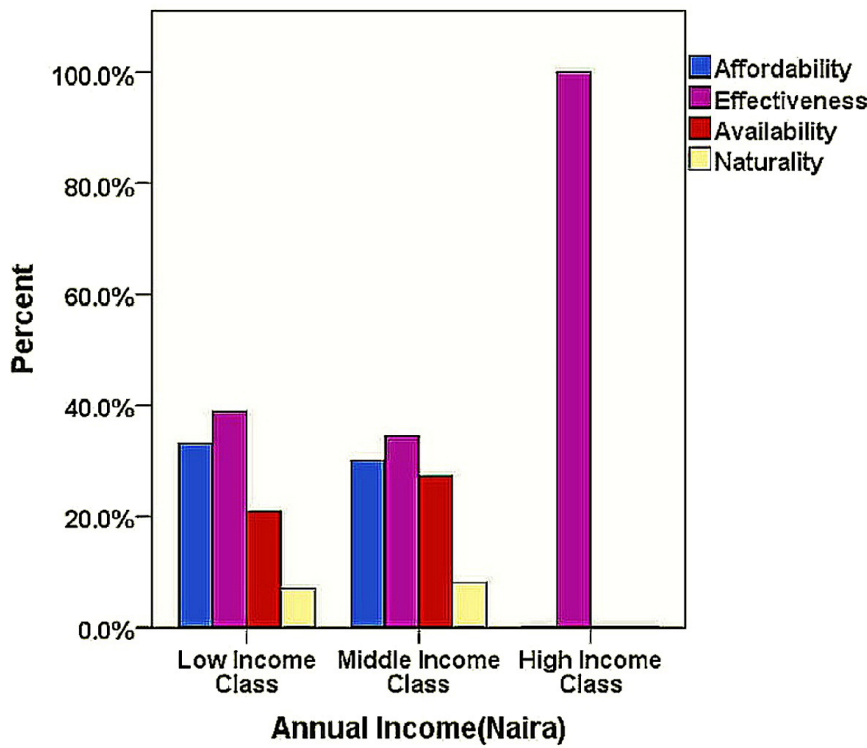

Figure 1 Chart showing reasons for herbal medicine use across economic background of respondents. 


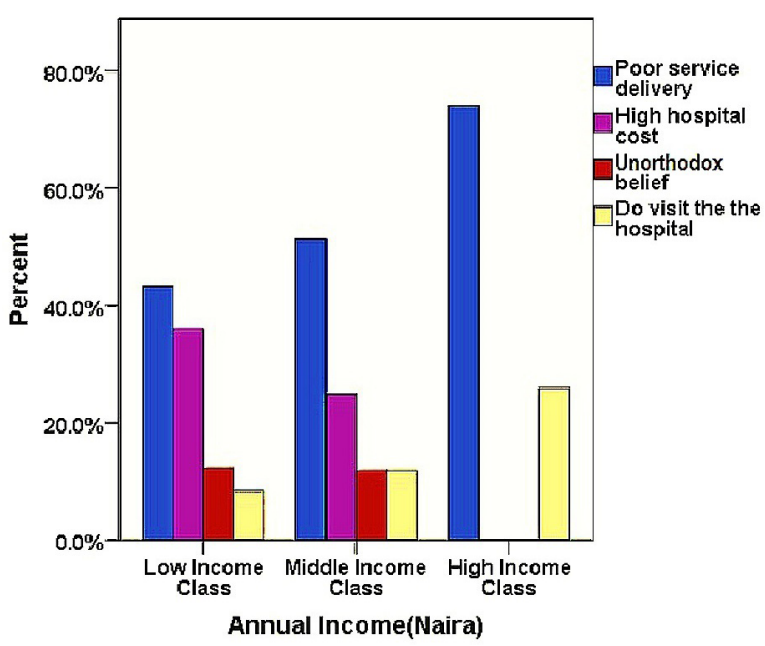

Figure 2 Chart showing reasons for non-hospital utilisation across economic background of the respondents.

A test of data for the assumption of collinearity showed multicollinearity was not an issue (age, tolerance $=0.86$, $\mathrm{VIF}=1.16$; gender, tolerance $=0.95, \mathrm{VIF}=1.05$; level of education, tolerance $=0.73, \mathrm{VIF}=1.38$; religion, tolerance $=0.89$, $\mathrm{VIF}=1.29$; occupation, tolerance $=0.83$, $\mathrm{VIF}=1.21$; annual income, tolerance $=0.85$, VIF $=1.17$ ).

\section{DISCUSSION}

Various studies have reported the use of HM in health subpopulation $^{30-33}$ and in different locations and settings. ${ }^{33-35}$ General population use of HM similar to

Table 4 Perception of herbal medicines' (HMs) safety and effectiveness and their adverse effect management

\begin{tabular}{lll}
\hline & Frequency & $\%$ \\
\hline Perception of effectiveness & & \\
\hline Effective & 899 & 83.6 \\
\hline Ineffective & 176 & 16.4 \\
\hline Perception of safety & & \\
Safe & 464 & 42.7 \\
Unsafe & 623 & 57.3 \\
\hline Observed adverse effect & & \\
\hline None & 566 & 52.7 \\
\hline Abdominal discomfort & 150 & 14.0 \\
\hline Nausea and vomiting & 201 & 18.7 \\
\hline Headache & 82 & 7.6 \\
\hline Stooling & 62 & 5.8 \\
\hline Generalised body weakness & 14 & 1.3 \\
\hline Management of adverse effect & & \\
\hline Rest and becomes self-limiting & 219 & 42.5 \\
\hline Visit the hospital & 129 & 25.0 \\
\hline Take orthodox medicine & 111 & 21.6 \\
\hline Take another HM & 56 & 10.9 \\
\hline
\end{tabular}

this study has been reported in South Africa, ${ }^{36}$ Benin, ${ }^{37}$ Uganda $^{38}$ and Nigeria. ${ }^{18}{ }^{39} 40$ But the prevalence of HM use in the general population is sparse in sub-Saharan Africa. However, prevalence study on the use of wider traditional complementary medicine reportedly varies from $4.6 \%$ in semi-urban Ethiopia ${ }^{41}$ to $94 \%$ in semi-urban Nigeria. ${ }^{42}$ The variability in prevalence could be a result of factors such as study design and method, socioeconomic variability of sample population, sample size and definition of terms in the study. Likewise the non-utilisation of conventional health system has been attributed to various reasons ${ }^{40} 43$; ; however, the socioeconomic peculiarity of the study population may also cause differences in findings. Historical and cultural use of HM in Africa presume adequate knowledge of HM already exists; but with the need for its regulation and certification, knowledge testing of the difference between certified and uncertified forms has therefore become more imperative.

In this study the majority of the respondents (90\%) knew the difference between government-certified and uncertified HMs. The high level of knowledge about certified and uncertified HMs may have been due to the success of various campaigns and public awareness programmes run by the NAFDAC in 2007 about fake and counterfeit drugs in Nigeria ${ }^{45}$ Participants' awareness is thus reflected in this study which is an indicator of the effectiveness of the government effort at sensitising the public.

However, we found that the use of HM is still high in the study population with $85 \%$ of the respondents having used them in the last 2 years (table 2). This high use has also been described in other African countries such as Ghana, Tanzania, Zambia, Kenya, and about $80 \%$ use reported in South Africa. ${ }^{46}$ Similar studies in general HM use conducted in Lagos and the UK reported $66.8 \%$ and $64.2 \%$ of their respondents had used HM. ${ }^{20}{ }^{47}$ Social, cultural, socioeconomic and political factors have been reported to influence the use of HM in developed countries, ${ }^{47} 48$ whereas this might not be the case in developing countries such as Nigeria. It has been reported that approximately $80 \%$ of Nigerians still consult the traditional healers for various healthcare provisions, ${ }^{49}$ which may explain the high use of HM in this study.

The effectiveness of HMs $(83.6 \%)$ was a major factor in their use which is in line with previous findings. ${ }^{440}$ Affordability was the second most mentioned factor $(31.9 \%)$ followed by availability $(21.5 \%)$. These factors influencing HM use in this study have also been reported previously. ${ }^{4}$ In addition, the authors reported other factors such as preference for natural therapies and complementary medicines, dissatisfaction with orthodox pharmaceuticals, high cost and side effects of orthodox medicine, distrust of physician's abilities and self-medication habit. ${ }^{4}$ Anecdotal information from friends, religious influence and spiritual consciousness have also been known to influence the use of HM. ${ }^{51}{ }^{52}$ Only $7.1 \%$ of the respondents in this study attributed their HM use to its natural and organic properties, the misconception of the natural 


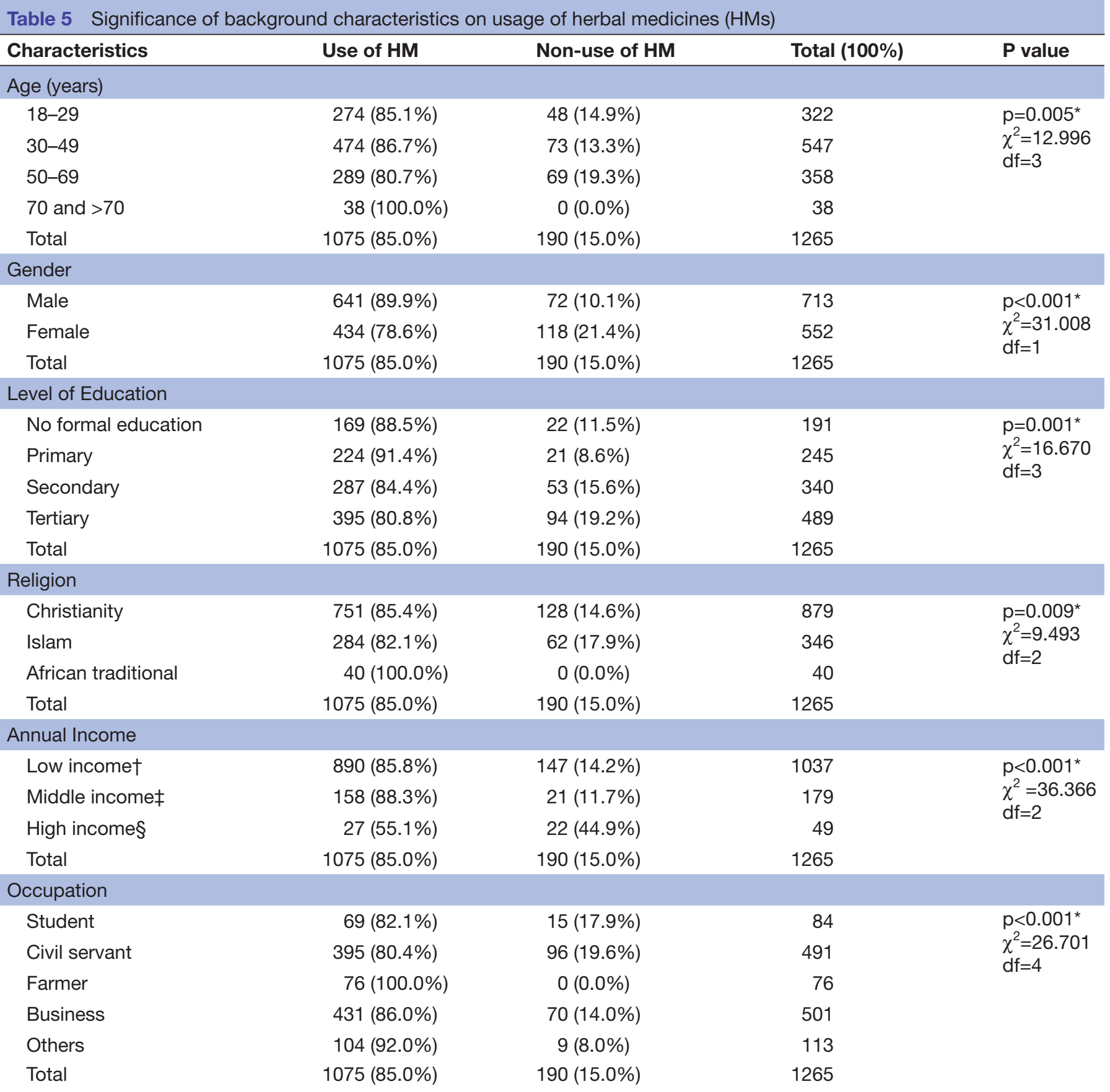

${ }^{*}$ Significant association.

$\dagger(\leq 600000$ naira $)$.

$\ddagger(601$ 000-2.4 million naira).

$\S(\geq 2.4$ million naira).

properties being non-toxic and free of adverse effect is a common belief in both developed and developing countries. ${ }^{53} \mathrm{~A}$ comparative assessment of herbal and orthodox medicines in Nigeria showed that the HMs were preferred to orthodox medicines in terms of efficacy, affordability, availability, safety and level of advertisement. ${ }^{40}$

The dissatisfaction with orthodox healthcare was also highlighted in this study. Majority of the respondents $(45.2 \%)$ attributed poor service delivery in the hospital to non-hospital utilisation followed by high hospital cost $(33.5 \%)$ (table 3$)$. The poor services experienced included long hospital waiting time, hostile and rude attitude of health workers, poor infrastructure and lack of communication. The nature of illness, availability of money, patient's age, religious or personal belief, level of education and severity of illness among other factors have been reported to influence the choice between orthodox and the traditional health system.

Nonetheless, challenges associated with the orthodox health system in Ekiti state such as affordability of service 
cost, quality of service rendered, closeness to home, staff attitude, environment cleanliness, availability of required drugs and services have also informed patient's patronage to the use of HM. ${ }^{54}$ In addition, approximately $70 \%$ of orthodox drugs in circulation in Nigeria are either adulterated or fake highlighting the need for thorough analysis of such products and licensing provisions.

Hence, findings from this study suggest lack of improvement in the healthcare service delivery over time, which is also evidenced by other publications highlighting similar issues. ${ }^{53}$ The effectiveness of HM and hospital poor service delivery are the reasons most highlighted in this study favouring HM use which is across the whole socioeconomic class of the respondents (figures 1 and 2). Thus, regardless of the economic situation of the respondents, a good service delivery in the orthodox health system is highly desirable.

A significant difference in the number of men using HM (89.9\%) was observed when compared with women $(78.6 \%) \quad\left(\mathrm{p}<0.001, \chi^{2}=31.008\right.$ and $\left.\mathrm{df}=3\right) \quad($ table 5$)$. Our finding is not consistent with published literature from developed countries where women had higher use of HM than men with $12.7 \%$ of women compared with $1.1 \%$ of men ${ }^{55}$ and $8.3 \%$ women compared with $2.9 \%$ of men ${ }^{56}$ with a similar trend reported in other studies. ${ }^{5758} \mathrm{~A}$ previous Nigerian study however found no significant difference between being women and use of HM. ${ }^{59}$ Although it has been reported that women take less risk than men, ${ }^{60}$ women tend to seek help from the orthodox healthcare when compared with men. ${ }^{60-63}$ Therefore, we recommend authorities to be mindful of targeting men in public health awareness in relation to the safety of HM.

The level of education was another factor that contributed to the use of HM in this study. There was significant relationship between respondent's level of education and use of HM ( $\left.p=0.001, \chi^{2}=16.670, d f=3\right)$, as respondents with primary level of education had the highest use of HM and least use within respondents with tertiary level of education. HM use was also highest among respondents within the middle annual income class while the least use was among the high annual income group $\left(\mathrm{p}=<0.001^{*}\right.$, $\left.\chi^{2}=36.366, \mathrm{df}=2\right)$. This finding contradicts a previous study where the author has reported poverty and dissatisfaction with orthodox medicine as the reason for HM use. ${ }^{64}$ In line with the author, our study showed dissatisfaction with orthodox medical care as a reason for non-hospital utilisation (table 3 ) but poverty was not a factor. ${ }^{64}$ Affordability which was the second most highlighted reason for use of HM (31.9\%) and high hospital cost which was the second most highlighted reason for non-hospital utilisation $(33.5 \%)$ may not equate to poverty. Though $82 \%$ of the respondents were within the low-income class, $69 \%$ of healthcare financing is still 'out of pocket' by patients in Nigeria. ${ }^{65}$ Health insurance accounts for only $2 \%$ of all healthcare financing in Nigeria. ${ }^{64}$

Therefore, financing out-of-pocket healthcare is an extra burden on a population with $82 \%$ already within the low-income group. This brings to bare the importance of the United Nations Sustainable Development Goal 3 , which is to strive towards achieving Universal Health Coverage by 2030 by all member states. ${ }^{66}$

Conversely, low level of education and income power has been reported to influence choice of HM use in previous studies. ${ }^{185767}$ The studies associated low income with the use of HM, which is different from what was found in this study. Highest use of HM was among the middle-income group (table 5). However, studies in developed countries have reported a non-significant relationship between income and HM use but a significant relationship between higher level of education and HM use. ${ }^{29} 68$ These variations may be due to interplay between factors such as respondent's socioeconomic characteristics and peculiarities of the study environment. Hence, the findings in this study reflect such interplay where the middle-income class used more HM and a significant relationship between level of education and HM use.

Additionally, there was a significant association between the age of the respondents and use of HM in this study $\left(\mathrm{p}=0.005, \chi^{2}=12.996, \mathrm{df}=3\right)$. Respondents 70 years and above have all (100\%) used HM in the last 2 years, followed by the age group 30-49 years of which $86.7 \%$ of them have also used HM within the period. A publication among the general population on HM use reported significant relationship between age and use of $\mathrm{HM},{ }^{57}$ while another reported no significant difference. ${ }^{18}$ This study showed that the use of HM increases with the age of the respondents, although age group 50-69 years did not follow this pattern. The occupation of the respondents was also significantly associated with HM use $(p=0.001$, $\chi^{2}=75.504 \mathrm{df}=8$ ). This can be linked to the annual income of the respondents which had significant association in this study. The type of occupation largely determines the accruable income.

There was $100 \%$ use of HM in the last 2 years among respondents who practised African traditional religion, $85.4 \%$ use among Christians and $82.1 \%$ use among Muslims. There was a significant relationship between religious affiliation of the respondents and HM use $\left(p=0.009, \chi^{2}=9.493, d f=2\right) \quad($ table 5$)$. The use of HM as an integral part of African traditional religion is documented and African traditional religionists being the custodian of the African traditional medicine. ${ }^{69}$ Although some studies reported no significant association between religion and HM use, ${ }^{363950}$ other studies have reported otherwise. ${ }^{70} 71$ Furthermore, research has shown that religious beliefs and spiritual practices of patients have powerful influence in making decision about treatment choice, coping with chronic diseases and end-of-life care decisions. ${ }^{72} 73$ Therefore, this study highlights the influence religion has on the use of HM; it is apparently a correlation between their religious belief and their choice of healthcare. There is no multicollinearity between the sociodemographic characteristics and the use of HM, therefore it reduces standard errors in related independent variables such as level of education, education and annual income. 
This study employed qualitative and quantitative data which catered for the peculiarity of the study population, hence increasing inclusivity. Also, the study has helped to reveal the prevalence and determinant of HM use and non-hospital utilisation within the study population. These are new findings within the Ekiti state which will help in public health planning. There were few limitations of this study. First, there were more incomplete entries in the self-administered questionnaires compared with the interview-administered ones, which reduced the number of eventual participants in the study. Second, most of the towns were visited during the day, at which farmers would have been away from the residential areas. This led to a low number of participants from this group compared with other occupations in this study. However, the eventual sample size was still representative of the study population. Also, there were possibilities for recall bias due to respondents' need to remember answers related to the previous 2 years, but the methodology used in this study is acceptable and robust for contemporary research in public health.

Further research may be needed to assess the use of HM in subhealth and the general population to increase present knowledge on HM use and ways to integrate traditional and orthodox healthcare systems within the study population.

\section{CONCLUSIONS}

Findings from this study showed majority of the study population have used HMs in the last 2 years regardless of the economic class. Majority of the respondents in the study know the difference between certified and uncertified HMs, but uncertified HMs were most commonly used. This study highlights the need for further investment in public health enlightenment and healthcare system. This is important considering the findings from this study on reasons for non-hospital utilisation corroborating the health infrastructural/service deficit which has been reported to influence the use of HMs in developing countries. However, the choices are limited; a choice between an acclaimed effective HM and an orthodox health system offering unsatisfactory service. While affordability was also an important reason people used HMs in this study, high hospital cost was also a reason people did not patronise orthodox medical service. It is a choice between an affordable HM and an expensive orthodox medical service especially in the absence of adequate health insurance coverage. This study has shown that there is a significant association between annual incomes, education, gender, age, religion and occupation with the use of HMs. Although there is a cultural history of HM use within the study population, socioeconomic and sociodemographic factors were determinants of its use in light of a prevalent income inequality and absence of adequate health insurance coverage.

Twitter Lata Gautam @LataGautam10 and Sarah Hall @SarahHa81702781
Contributors OA designed and implemented the work; carried out data analysis and interpretation; drafted the manuscript; and is accountable for the accuracy and integrity of the work. LG designed and supervised the work; carried out interpretation; drafted and revised the manuscript for final approval; and is accountable for the accuracy and integrity of the work. PS advised on public health aspect of the research and carried out interpretation and revision of the manuscript. SH supervised the work; carried out interpretation; drafted and revised the manuscript for final approval; and is accountable for the accuracy and integrity of the work.

Funding The authors have not declared a specific grant for this research from any funding agency in the public, commercial or not-for-profit sectors.

\section{Competing interests None declared.}

Patient consent for publication Not required.

Ethics approval Ethics approval was obtained from the Faculty of Science and Technology, Anglia Ruskin University and Ekiti State Ministry of Health in Ekiti state. Participants were provided with the participant information sheet and the content explained in English or local dialect. Informed consent was obtained from the participants who volunteered to be part of the study.

Provenance and peer review Not commissioned; externally peer reviewed.

Data availability statement No data are available. All data relevant to the study are included in the article.

Open access This is an open access article distributed in accordance with the Creative Commons Attribution Non Commercial (CC BY-NC 4.0) license, which permits others to distribute, remix, adapt, build upon this work non-commercially, and license their derivative works on different terms, provided the original work is properly cited, appropriate credit is given, any changes made indicated, and the use is non-commercial. See: http://creativecommons.org/licenses/by-nc/4.0/.

ORCID iD

Lata Gautam http://orcid.org/0000-0002-0409-4724

\section{REFERENCES}

1 Frass M, Strassl RP, Friehs $\mathrm{H}$, et al. Use and acceptance of complementary and alternative medicine among the general population and medical personnel: a systematic review. Ochsner J 2012;12:45-56.

2 World Health Organization (WHO). Traditional complementary and integrative medicine. Available: https://www.who.int/traditionalcomplementary-integrative-medicine/about/en/ [Accessed 03 Nov 2019].

3 Bodeker C, Bodeker G, Ong CK, et al. WHO global atlas of traditional, complementary and alternative medicine. Geneva, Switzerland: WHO, 2005.

4 Bandaranayake WM. Quality Control, Screening, Toxicity, and Regulation of Herbal Drugs. In: Modern Phytomedicine. Turning medicinal plants into drugs. Weinheim: Wiley-VCH GmbH \& Co. KGaA, 2006: 25-57.

5 Nissen N. Practitioners of Western herbal medicine and their practice in the UK: beginning to sketch the profession. Complement Ther Clin Pract 2010;16:181-6.

6 Calapai G. European legislation on herbal medicines: a look into the future. Drug Saf 2008;31:428-31.

7 Romero-Daza N. Traditional medicine in Africa. Ann Am Acad Pol Soc Sci 2002;583:173-6.

8 Abdullahi AA. Trends and challenges of traditional medicine in Africa. Afr J Tradit Complement Altern Med 2011;8:115-23.

9 MacGaffey W. African traditional religion. Oxford bibliographies. Available: http://www.oxfordbibliographies.com/view/document/ obo-9780199846733/obo-9780199846733-0064.xml\#firstMatch [Accessed 25 Jul 2020].

10 Oguntomisin GO. Political change and adaptation in Yorubaland in the nineteenth century. Can J Afr Stud 1981;15:223-37.

11 Olayiwola DO. The Aladura: It's Strategy for Mission and Conversion in Yoruba land, Nigeria. Orita: Ibadan J Rel Stud 1987;19:40-56.

12 Mills E, Cooper C, Seely D, et al. African herbal medicines in the treatment of HIV: Hypoxis and Sutherlandia. An overview of evidence and pharmacology. Nutr J 2005;4:19.

13 Van Wyk BE, Van Oudtshoorn B, Gericke N. Medicinal plants of South Africa. 336. Pretoria: Briza Publications, 1999. ISBN: 978-1875093-37-3.

14 Onwuanibe RC. The philosophy of African medical practice. Issue: $A$ Journal of Opinion 1979;9:25-8. 
15 Helwig D. Traditional African medicine. Gale encyclopedia of alternative medicine. Available: http://www.encyclopedia.com/doc/ 1G2-3435100785.html [Accessed 24 Jul 2020].

16 Olorunniyi OF, Morenikeji OA. The extent of use of herbal medicine in malaria management in Ido/Osi local government area of Ekiti state, Nigeria. J Med Plants Res 2013;7:3171-8.

17 Awodele O, Amagon KI, Usman SO, Kennedy IA, Sikiru OU, et al. Safety of herbal medicines use: case study of ikorodu residents in Lagos, Nigeria. Curr Drug Saf 2014;9:138-44.

18 Okoronkwo I, Onyia-Pat J-L, Okpala P, et al. Patterns of complementary and alternative medicine use, perceived benefits, and adverse effects among adult users in Enugu urban, Southeast Nigeria. Evid Based Complement Alternat Med 2014;2014:1-6.

19 Duru CB, Uwakwe KA, Chinomnso NC, et al. Socio-Demographic determinants of herbal medicine use in pregnancy among Nigerian women attending clinics in a tertiary hospital in Imo state, SouthEast, Nigeria. Am J Med 2016;4:1-10.

20 Oreagba IA, Oshikoya KA, Amachree M. Herbal medicine use among urban residents in Lagos, Nigeria. BMC Complement Altern Med 2011;11:117

21 NAFDAC guidelines herbal and cosmetics. Available: https://www. nafdac.gov.ng/resources/guidelines/ [Accessed 20 Jul 2020].

22 Ekiti state government strategic health development plan 2010-2015, 2011. Available: https://drive.google.com/file/d/OB1DAmtM1Bcb MVXpvRlhxaUdYOFU/view [Accessed 20 Jul 2020].

23 National Bureau of Statistics (NBS). Poverty and inequality in Nigeria: Executive summary. available at, 2019. Available: https://nigerianstat. gov.ng/download/1092 [Accessed 20 Jul 2020].

24 Odeyemi CA. Spatial distribution of poverty indicators in Ekiti state. Dev Ctry Stud 2014;4:119.

25 National Population Commission. Census report, 2006. Available: https://nigeriacrvs.gov.ng [Accessed 03 Nov 2019].

26 Ekiti state government EKSG, 2016. Available: https://ekitistate.gov. ng/about-ekiti/ [Accessed 03 Nov 2019].

27 Cochran WG. Sampling techniques. 3rd Ed. New York: Wiley, 2007.

28 Bryman A, Cramer D. Quantitative data analysis for social scientists. London, New York: Routledge, 1990.

29 Kummet CM, Spector ML, Dawson DV, et al. Patterns of complementary and alternative medicine (CAM) use among dental patients. J Public Health Dent 2015;75:109-17.

30 Olusanya BO, Inem VA, Abosede OA. Infants delivered in maternity homes run by traditional birth attendants in urban Nigeria: a community-based study. Health Care Women Int 2011;32:474-91.

31 Sarmiento I, Zuluaga G, Andersson N. Traditional medicine used in childbirth and for childhood diarrhoea in Nigeria's cross river state: interviews with traditional practitioners and a statewide crosssectional study. BMJ Open 2016;6:e010417.

32 Girma E, Tesfaye M. Patterns of treatment seeking behavior for mental illnesses in Southwest Ethiopia: a hospital based study. BMC Psychiatry 2011;11:138.

33 Awodele O, Agbaje EO, Abiola OO, et al. Doctors' attitudes towards the use of herbal medicine in Lagos, Nigeria. $J$ Herb Med 2012;2:16-22.

34 Mbutho NP, Gqaleni N, Korporaal CM. Traditional complementary and alternative medicine: knowledge, attitudes and practices of health care workers in HIV and AIDS clinics in Durban hospitals. Afr $J$ Tradit Complement Altern Med 2012;9:64-72.

35 van Staden AM, Joubert GBA. Interest in and willingness to use complementary, alternative and traditional medicine among academic and administrative university staff in Bloemfontein, South Africa. Afr J Tradit Complement Altern Med 2014;11:61-6.

36 Hughes GD, Aboyade OM, Clark BL, et al. The prevalence of traditional herbal medicine use among hypertensives living in South African communities. BMC Complement Altern Med 2013;13:38.

37 Allabi AC, Busia K, Ekanmian V, et al. The use of medicinal plants in self-care in the Agonlin region of Benin. $J$ Ethnopharmacol 2011;133:234-43.

38 Auerbach BJ, Reynolds SJ, Lamorde M, et al. Traditional herbal medicine use associated with liver fibrosis in rural Rakai, Uganda. PLoS One 2012;7:e41737.

39 Opara ER, Osayi KK. Factors affecting the utilization of herbal medicine as a Livelihood alternative among residents of IMO state: the role of social work professionals. IOSR-JHSS 2016;21:66-78.

40 Osemene KP, Elujoba AA, Ilori MO. A comparative assessment of herbal and orthodox medicines in Nigeria. Res J. Med Sci 2011;5:280-5.

41 Flatie T, Gedif T, Asres K, et al. Ethnomedical survey of Berta ethnic group Assosa zone, Benishangul-Gumuz regional state, mid-west Ethiopia. J Ethnobiol Ethnomed 2009;5:14.
42 Sarki ZM, Danjuma MH. Socio-Demographic factors and utilization of traditional medicine in Kazaure town, Jigawa state, Nigeria. Int $J$ Emerg Know 2015;3:9-20.

43 Aikins I, Ahmed M, Adzimah ED. Assessing the role of quality service delivery in client choice for healthcare: a case study of Bechem government hospital and green Hill Hospital. Eur J Purch Supply Manag 2014;2:1-23.

44 Adesiji GB, Komolafe SE. Factors influencing the use of traditional healing among farmers in Kwara state, Nigeria. Albanian J Agric Sc 2013;12:275-81.

45 Ofuani AB, Kuye OL, Ogundele OJK. An assessment of the efficiency of government regulatory agencies in Nigeria. Case of the National agency for food and drugs administration and control. Acad J Econ Stud 2015;1:9-26.

46 Ozioma EOJ, Nwamaka OA. Herbal medicines in African traditional medicine, 2019. Available: https://www.intechopen.com/books/ herbal-medicine/herbal-medicines-in-african-traditional-medicine [Accessed $20 \mathrm{Jul}$ 2020].

47 Ong P, Bodeker G. Use of complementary and alternative medicine services in England. Am J Public Health 2002;92:1653-6.

48 Eskinazi D. Factors that will Shape the Future of Alternative Medicine: An Overview. In: What will influence the future of alternative medicine? A world perspective. Singapore: World Scientific Publishers, 2001: 1-22.

49 Adefolaju T. Traditional and orthodox medical systems in Nigeria: the imperative of a synthesis. AJHR 2014;2:118-24.

50 Mafimisebi TE, Oguntade AE. Health Infrastructure Inequality and Rural-Urban Utilization of Orthodox and Traditional Medicines in Farming Households: A Case Study of Ekiti State, Nigeria. In: Smigorski K, ed. Health Management - Different Approaches and Solutions. In Tech, 2011: 197-214.

51 Astin JA. Why patients use alternative medicine: results of a national study. JAMA 1998;279:1548-53.

52 Zeil $\mathrm{H}$. Complementary alternative medicine boon or boondoggle. Skeptic 1999;7:86-9.

53 Wertheimer Al, Wang PG. Countrfeit medicines. policy, economies and counter measures. First Edition. ILM Publications USA, 2012: 1-3.

54 Omotoso D. Health seeking behaviour among the rural dwellers in Ekiti state, Nigeria. Afr. Res. Rev. 2010;4:125-38.

55 Harrison RA, Holt D, Pattison DJ, et al. Who and how many people are taking herbal supplements? A survey of 21,923 adults. Int J Vitam Nutr Res 2004;74:183-6.

56 Raji MA, Kuo Y-F, Snih SA, et al. Ethnic differences in herb and vitamin/mineral use in the elderly. Ann Pharmacother 2005;39:1019-23.

57 Gardiner P, Graham R, Legedza ATR, et al. Factors associated with herbal therapy use by adults in the United States. Altern Ther Health Med 2007:13:22-9.

58 Bakhotmah BA, Alzahrani HA. Self-Reported use of complementary and alternative medicine (CAM) products in topical treatment of diabetic foot disorders by diabetic patients in Jeddah, Western Saudi Arabia. BMC Res Notes 2010;3:254.

59 Onyeka TC, Ezike HA, Nwoke OM, et al. Herbal medicine: a survey of use in Nigerian presurgical patients booked for ambulatory anaesthesia. BMC Complement Altern Med 2012;12:130.

60 Harris CR, Jenkins M. Gender differences in risk assessment. why do women take fewer risks than men? Judgm Decis Mak 2006;1:48-63.

61 Green CA, Pope CR. Gender, psychosocial factors and the use of medical services: a longitudinal analysis. Soc Sci Med 1999;48:1363-72.

62 Bertakis KD, Azari R, Helms LJ, et al. Gender differences in the utilization of health care services. J Fam Pract 2000;49:147.

63 Chang H-J, Lai Y-L, Chang C-M, et al. Gender and age differences among youth, in utilization of mental health services in the year preceding suicide in Taiwan. Community Ment Health $J$ 2012;48:771-80.

64 Oshikoya KA, Senbanjo IO, Njokanma OF, et al. Use of complementary and alternative medicines for children with chronic health conditions in Lagos, Nigeria. BMC Complement Altern Med 2008;8:66.

65 Uzochukwu BSC, Ughasoro MD, Etiaba E, et al. Health care financing in Nigeria: implications for achieving universal health coverage. Niger J Clin Pract 2015;18:437-44.

66 Sustainable Development Goal (SDG). Sustainable development knowledge platform. Available: https://sustainabledevelopment.un. org/sdg3 [Accessed $20 \mathrm{Jul}$ 2020].

67 Barnes PM, Bloom B, Nahin RL. Complementary and alternative medicine use among adults and children: United States, 2007. Natl Health Stat Report 2008;10:1-23. 
68 Du Y, Wolf I-K, Zhuang W, et al. Use of herbal medicinal products among children and adolescents in Germany. BMC Complement Altern Med 2014;14:218.

69 White P. The concept of diseases and health care in African traditional religion in Ghana. HTS Teologiese Studies / Theological Studies 2015;71:1-7.

70 Hulela K, Thobega M. Botswana Faith Leaders' Attitudes towards the Use of Indigenous Medicinal Herbs. J Med Plants Res 2013;7:1550-6.
71 Nicdao EG, Ai AL. Religion and the use of complementary and alternative medicine (cam) among cardiac patients. J Relig Health 2014;53:864-77.

72 Puchalski CM. Spirituality and health: the art of compassionate medicine. Hospital Physician 2001:30-6.

73 McCormick TR, Hopp F, Nelson-Becker $\mathrm{H}$, et al. Ethical and spiritual concerns near the end of life. $J$ Relig Spiritual Aging 2012;24:301-13 